\title{
Does participation in the Food and Health Project impact on participants understanding of food labels?
}

\author{
S. Kleemann ${ }^{1}$, C. Cunningham ${ }^{1}$, C. Glennon Slattery ${ }^{1}$ and R. McEvoy ${ }^{2}$ \\ ${ }^{1}$ Community Nutrition and Dietetic Service, Health Service Executive Dublin Mid Leinster, Marlinstown Office Park, \\ Mullingar, Co. Westmeath, Republic of Ireland and ${ }^{2}$ Clinical Audit Department, Health Service Executive Dublin \\ Mid Leinster, Tullamore, Co. Offaly, Republic of Ireland
}

Food labelling by industry is an attempt to provide consumers, at the point of purchase, with information about the nutrition content of individual food products, in order to enable consumers to choose nutritionally-appropriate food ${ }^{(1)}$. However, it has been shown that respondents from lower educational and social class groupings are significantly less likely to look at information on food labels ${ }^{(2)}$.

A partnership programme, The Food and Health Project, was set up in the Midland region of Ireland between the Health Service Executive, Dublin Mid Leinster and Westmeath Community Development Ltd in 1999. The project aims to increase nutritional knowledge and improve eating practice among disadvantaged groups. A six-session course is delivered over a 6-week time-frame by peer instructors to groups of adult men and women by means of a peer-led nutrition education programme.

The aim of the present study was to determine the level of participants' reading and understanding of food labels, pre- and post intervention. The structured questionnaire used to collect data was administered on the first day of the 6-week intervention programme under the supervision of the peer-led educator and again on the final day of the programme. A total of sixteen open and closed questions were included in the pre-intervention questionnaire and twenty-one questions in the post-intervention questionnaire. The questionnaire was approved by the National Adult Literacy Association of Ireland and also piloted amongst health professionals and previous course participants. Pre- and post intervention 101 questionnaires were completed and submitted for analysis. Data from the questionnaires were analysed using SPSS software v.14 (SPSS Inc., Chicago, IL, USA). Generally, the results presented draw on basic descriptive statistics such as frequency and percentage tables for each question on the questionnaire. Pearson's $\chi^{2}$ test was also carried out where appropriate. Results show that there was a significant association $\left(\chi^{2} 10.471\right.$, df $\left.2, P<0.05\right)$ between the intervention and the number of participants reportedly reading food labels. There was also a significant association $\left(\chi^{2} 8.301\right.$, df $\left.2, P<0.05\right)$ between the intervention and the reported level of understanding in relation to food labels. The percentages of participants who reported reading and those understanding food labels pre- and post intervention are shown in the Table:

\begin{tabular}{lcccc}
\hline & Yes & No & Sometimes & Not applicable \\
\hline Participants reading food labels & & & & \\
$\quad$ Pre-intervention & 31.5 & 20.2 & 48.0 & 0.0 \\
$\quad$ Post intervention & 46.5 & 6.0 & 47.0 & 0.0 \\
Participants understanding food labels & & & 47.6 & 2.4 \\
$\quad$ Pre-intervention & 39.3 & 10.7 & 50.0 & 0.0 \\
$\quad$ Post intervention & 48.7 & 1.3 & &
\end{tabular}

The present study shows that peer-led interventions can achieve positive changes in outcomes such as the reading and understanding of food labels. The findings presented will aid in future course-material development and peer instructor training.

1. Grunert KG \& Wills JM (2007) J Public Health 15, 385-399.

2. National Nutrition Surveillance Centre (2003) Dietary habits of the Irish population: Results from SLÁN. http://www.dohc.ie/publications/pdf/ diethab.pdf?direct=1 